Research Article

\title{
Tuning, Impedance Matching, and Temperature Regulation during High-Temperature Microwave Sintering of Ceramics
}

\author{
Sylvain Marinel $\mathbb{D}^{\mathrm{D}},{ }^{1}$ Nicolas Renaut, ${ }^{1}$ Etienne Savary, ${ }^{1,2}$ Rodolphe Macaigne, \\ Guillaume Riquet, ${ }^{1}$ Christophe Coureau, ${ }^{3}$ Thibault Gadeyne, ${ }^{4}$ and David Guillet ${ }^{4}$ \\ ${ }^{1}$ Laboratoire de Cristallographie et Sciences des Matériaux, Normandie Univ, ENSICAEN, UNICAEN, CNRS, CRISMAT, \\ 14000 Caen, France \\ ${ }^{2}$ Université de Valenciennes et du Hainaut-Cambrésis, Boulevard du Général de Gaulle, 59600 Maubeuge, France \\ ${ }^{3}$ SOLCERA, ZI n 1 rue de l'industrie, 27000 Evreux, France \\ ${ }^{4}$ SAIREM, 12 Porte du Grand Lyon, 01702 Neyron, France
}

Correspondence should be addressed to Sylvain Marinel; sylvain.marinel@ensicaen.fr

Received 5 February 2018; Revised 18 April 2018; Accepted 22 April 2018; Published 17 May 2018

Academic Editor: Joon-Hyung Lee

Copyright (c) 2018 Sylvain Marinel et al. This is an open access article distributed under the Creative Commons Attribution License, which permits unrestricted use, distribution, and reproduction in any medium, provided the original work is properly cited.

\begin{abstract}
Over the years, microwave radiation has emerged as an efficient source of energy for material processing. This technology provides a rapid and a volumetric heating of material. However, the main issues that prevent microwave technology from being widespread in material processing are temperature control regulation and heating distribution within the sample. Most of the experimental works are usually manually monitored, and their reproducibility is rarely evaluated and discussed. In this work, an originally designed $915 \mathrm{MHz}$ microwave single-mode applicator for high-temperature processing is presented. The overall microwave system is described in terms of an equivalent electrical circuit. This circuit has allowed to point out the different parameters which need to be adjusted to get a fully controlled heating process. The basic principle of regulation is then depicted in terms of a block function diagram. From it, the process has been developed and tested to sinter zirconia- and spinel-based ceramics. It is clearly shown that the process can be successfully used to program multistep temperature cycles up to $\sim 1550^{\circ} \mathrm{C}$, improving significantly the reproducibility and the ease of use of this emerging high-temperature process technology.
\end{abstract}

\section{Introduction}

In recent years, microwave energy has been successfully used for processing many materials, including the fast synthesis of various inorganic compounds and the sintering of ceramics. Kitchen et al. [1] have recently published an overview paper describing different works related to the solid state synthesis of widely spread oxides $\left(\mathrm{BaTiO}_{3}\right.$, spinel phase, $\mathrm{BaZrO}_{3}$, etc.), carbides ( $\mathrm{TiC}, \mathrm{WC}, \mathrm{Mo}_{2} \mathrm{C}$, etc.), or nitrides $\left(\mathrm{AlN}, \mathrm{Ta}_{2} \mathrm{~N}\right.$, etc.) using microwave energy. Microwave energy has also been successfully used to sinter various materials. For instance, Brosnan et al. [2] have sintered alumina in using a $2.45 \mathrm{GHz}$ hybrid microwave multimode cavity. Many other works have reported similar results on various materials, mostly oxide ceramics [3-6]. All these processing methods obviously imply a high-temperature stage $\left(>1200^{\circ} \mathrm{C}\right)$ and, in comparison to conventional technologies involving infra-red radiation heating sources (electrical or gas furnaces), the microwave technology is known to be faster and greener, with less energy consumption. Bykov et al. [7] have written an interesting overview underlining the specific advantages of microwave sintering over conventional processes. Most especially, it is well established that taking into consideration the penetration depth of the microwave electrical field $(E)$, which is a few centimeter in most oxide materials, the heat is volumetric generated. Starck et al. [8] indeed reported that the penetration depth of microwaves at $2.45 \mathrm{GHz}$ into alumina is 
around $1.5 \mathrm{~cm}$ at room temperature. This is a great advantage over infra-red conventional heating, for which the penetration depth of the radiation is a few $\mu \mathrm{m}$. As a result, the energy is transferred through the material by direct microwave-matter coupling, not as a thermal heat flux. Consequently, the rate of heating is often high, and the uniformity of heat distribution is greatly improved [9]. All these features undeniably contribute to the high efficiency of the microwave thermal process. However, up to now, the main issues that prevent the microwave technology from being widespread used at a larger scale, including the industrial scale, is temperature control regulation, which also means its measurement and its distribution within the sample. This is even truer when high temperature processes $\left(>1200^{\circ} \mathrm{C}\right)$ are involved, and the final microstructure must be carefully controlled. Regarding the temperature measurement, Macaigne et al. [10] have recently published a paper describing an original method to measure the thermal emissivity of a material being microwave heated, allowing to measure with high confidence the actual material temperature by a infra-red single-color pyrometer. It is worthy to mention that this method takes into account the emissivity temperature dependence, which is of primary importance for precisely measuring the temperature by a pyrometer. This method is nowadays used in our laboratory. However, up to now, very few methods have been reported to automatically regulate the temperature of samples which are being heat treated in a microwave single-mode applicator. Most of the time the temperature is measured by an infrared pyrometer, and the regulation is performed manually: the operator usually adjusts both the incident microwave power and the resonance mode of the cavity so that the sample temperature follows the desired thermal cycle. This later method works but is obviously not appropriate when high robustness and reliability are required. In this work, the goal was to be able to program a multistep thermal cycle in a large temperature range (from room temperature to $\sim 1600^{\circ} \mathrm{C}$ ). In the literature, only few articles deal with automatic temperature regulation during hightemperature microwave processing of materials. Vogt et al. [11] from Los Alamos Laboratory (Defense National USA laboratory) have reported an interesting method implying a rapid feedback control system operating with a traveling wave tube amplifier for the regulation of the sintering temperature of bars and tubes in a single-mode microwave cavity. This method was tested to sinter NICALON, which is a multifilament silicon carbide fiber, at roughly $1100^{\circ} \mathrm{C}$. The described method was based on automatically adjusting the microwave generator power and frequency (centered around $2.94 \mathrm{GHz}$ ) to follow-up the desired temperature. It is important to mention that as temperature increases, the cavity load impedance changes (since the physical properties of the load depend on the temperature), and therefore, the conditions to get a good microwave material absorption vary. However, this method is not really applicable since most of the microwave generators used in the laboratory and industry are working at a fixed frequency (usually $2.45 \mathrm{GHz}$ or $915 \mathrm{MHz}$ ). Although the importance of the impedance matching and cavity tuning

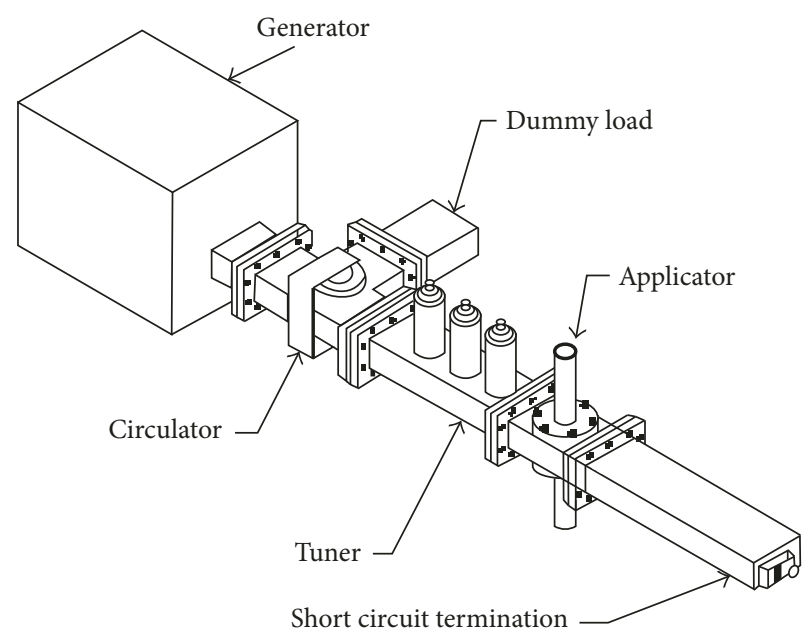

FIgURE 1: A typical laboratory set-up used for material processing at high temperature in a single-mode microwave cavity.

has been already found and discussed in medicine for microwave exposure to biological tissue [12] (at, obviously, a low temperature), those aspects are rarely evoked in hightemperature microwave processes. Thus, in this work, an original process will be described which allows to automatically regulate the temperature of a material being heat treated by a microwave up to $1600^{\circ} \mathrm{C}$. This process uses a common fixed frequency, that is, $915 \mathrm{MHz}$. First of all, the microwave system will be described in terms of an equivalent electrical circuit. Based on this circuit, the various impedance components and relevant parameters will be defined. Afterwards, the overall basic principle of temperature regulation will be described in terms of a block function diagram. Finally, the process will be tested to sinter at high temperatures (up to $1600^{\circ} \mathrm{C}$ ) on some widely spread oxides, including zirconia and spinel.

\section{Experimental and Results}

2.1. Experimental Microwave Set-Up. Figure 1 shows a typical laboratory set-up used for material processing at high temperature in a single-mode microwave cavity. The microwave generator delivers a microwave power towards a rectangular wave guide directly connected to a circulator. The latter is used for the protection of the generator from the damaging effects of the reflected microwave power. The circulator absorbs the reflected power through a dummy load. This circulator is followed by a conventional rectangular wave guide equipped with a tuner.

Coupling microwave power to a load requires the respective complex impedance between the load and the microwave power source to be matched. Manually adjusted tuners, as the one shown in Figure 1, are by far the most common for industrial and laboratory heating applications. A simple design indeed, widely used, employs three threaded stubs screwed directly through the broad wall of the wave guide. Still, operating a manual tuner is mostly a practiced work that can only be learned from experience. In this work, an automatic tuner will be used in order to keep 


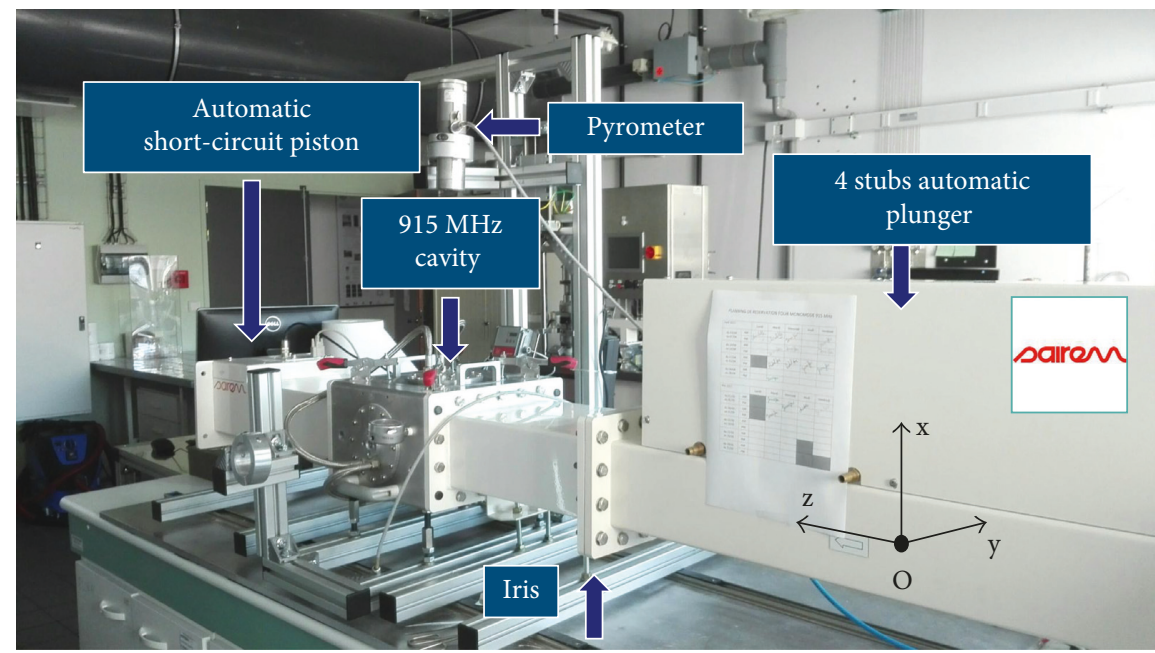

FIgURE 2: Photograph showing the overall $915 \mathrm{MHz}$ microwave process. The short circuit motorization and the 4 stubs automatic plunger are connected to a personal computer and can be monitored by it.

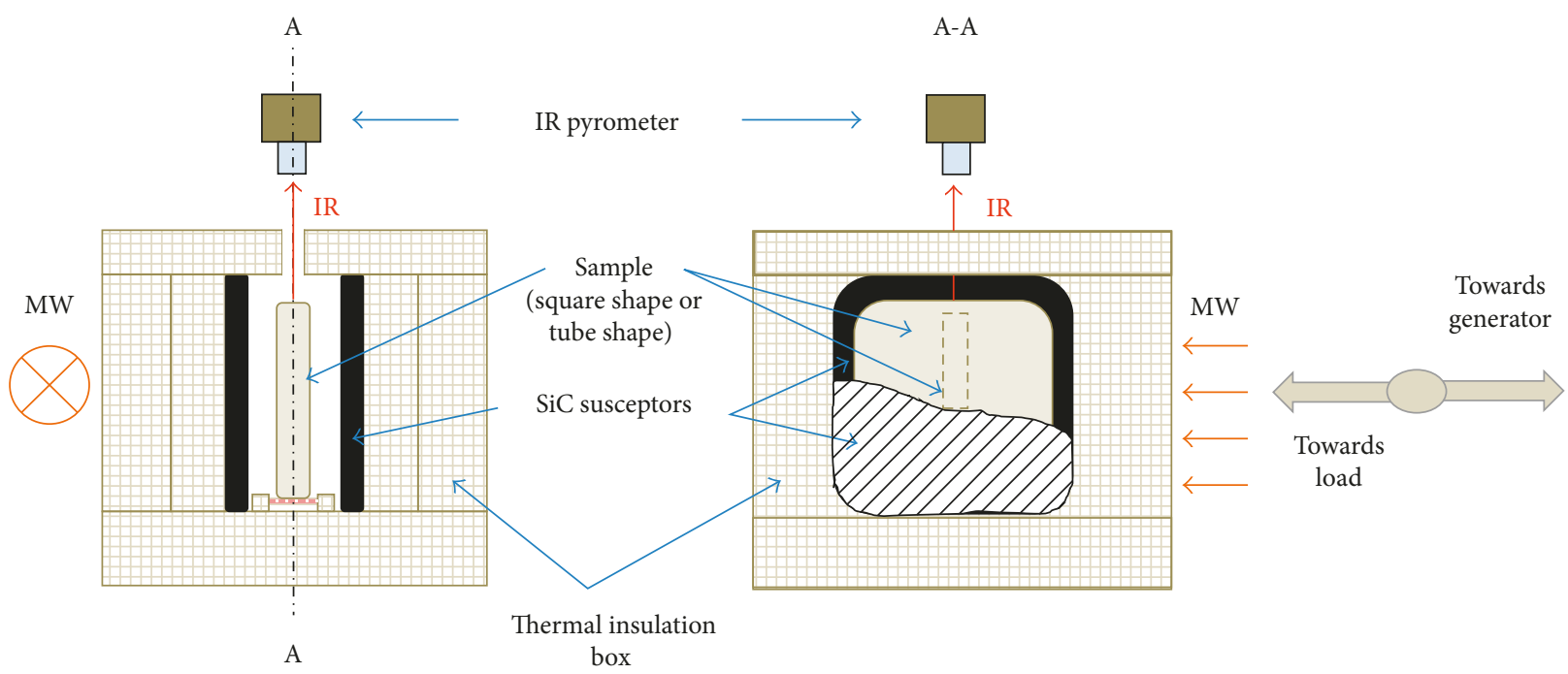

FIGURE 3: Scheme showing the assembly used to heat up the ceramic green sample into the $915 \mathrm{MHz}$ single-mode cavity.

up with the dynamics of the heating process. Otherwise, with an automatic system, a better impedance match can be achieved within milliseconds while the manual impedance process usually takes a few seconds. For more information regarding the function of each microwave components, Gerling et al. [13] have published an interesting technical review. Following the tuner, there is the resonant cavity, in which the sample will be heat treated. Finally, to tune the resonance mode, a movable short circuit termination is used at the end of the line as shown in Figure 1. Taking into account our goal to get a fully automatic heating process, the basic principle depicted on Figure 1 has been modified in first, using an automatic 4 stubs impedance plunger (AI4S from SAIREM) and second, using a motorized short circuit piston/termination. Figure 2 shows a photograph of the overall microwave process that includes the $915 \mathrm{MHz}-5 \mathrm{~kW}$ generator from SAIREM (not shown on the photograph), an automatic impedance tuner based on a $2 \times 2$ tuning plungers (AI4S from SAIREM)), and a resonant applicator, delimited by a fixed iris and a short motorized circuit termination.

2.2. Microwave Heating Assembly. The microwave assembly designed for our purpose is shown in Figure 3. The sample having a square or a cylindrical shape is vertically mounted onto an alumina support piece. In case of a square shape sample, the larger side of the sample is aligned along the microwave propagation direction (see the " $Z$ " direction). In case of a cylindrical shape, the cylinder axis is parallel to the $\mathrm{X}$ direction (vertical direction). Two $\mathrm{SiC}$ pieces are used as susceptors to initiate the sample heating especially for the low loss dielectric material. These two pieces are schematically positioned as shown in Figure 3. The susceptors allow to rapidly heat up the samples. The susceptors are two hot surfaces in front of the large side of the sample that prevent it from being too rapidly cooled by thermal radiation. This geometry was demonstrated to be efficient to 
homogenize the temperature within the sample. Finally, the overall assembly, made from the sample and susceptors, is introduced into a thermal insulation box made of a microwave transparent refractory material (alumina-silicate porous foam from RATH). The transverse electric (TE 105) mode is tuned so that the sample, located in the center of the cavity, is subjected to a maximum of the electrical field ( $E$ field). Temperature is measured by a single-color pyrometer (IRCON modline $5 \mathrm{G}$ ) which targets on the edge of the sample and for which the temperature range is $350^{\circ} \mathrm{C}<\theta<2000^{\circ} \mathrm{C}$. Single-color pyrometer was used instead of a 2-color pyrometer since the apparent emissivity of the material and its environment can be measured using the method previously developed in the laboratory by Macaigne et al. [10]. By this method, the apparent emissivity was found to be 0.7 at $\sim 1500^{\circ} \mathrm{C}$ for spinel, and a similar value was measured for zirconia. It must be understood that the thermal radiation received by the IR pyrometer comes from the material and its environment (thermal radiation from the susceptors). The environment being the same for both materials (Figure 3), as well as the maximum temperature $\left(\sim 1500^{\circ} \mathrm{C}\right)$, the apparent emissivity remains nearly constant regardless the material (zirconia or spinel). Consequently, the value of the emissivity was fixed at 0.7 for all experiments.

\subsection{Analogous Electrical Circuit: Microwave Heating Process.} Based on our experimental set-up, an analogous electrical circuit of the overall microwave process can be drawn (Figure 4(a)). This analogous circuit is well known in microwave engineering, and more particularly in telecommunication science [14], but is practically not used by chemists working with microwaves for high-temperature processing and power applications.

The microwave generator is represented by a voltage source $\left(E_{0}\right)$ with its internal resistance $\left(R_{0}\right)$. The 4 stubs tuning plunger with the iris is modeled as an " $n$ turn" transformer. The resonant cavity is represented by a resonant LC circuit with a resonant angular velocity $(\omega=(1 / \sqrt{\mathrm{LC}}))$. It is worthwhile mentioning that the resonance conditions of the microwave cavity are properly adjusted by moving the short circuit piston position to match with the fixed frequency (in doing so, $L$ and $C$ change). In an $(L, C)$ electrical conventional circuit, the resonance conditions are tuned by adjusting the frequency of the electrical signal. Finally, Joule losses within the cavity wall and into the sample which is being heated is represented by a series resistance $(r)$. It is essential to mention that considering the sample temperature increasing from room temperature to high temperature (above $1500^{\circ} \mathrm{C}$ ), a large variation of its physical properties is expected during the heating process. For instance, Heiroth et al. [15] have measured the electrical conductivity of yttrium-stabilized zirconia varying from $4.10^{-5} \mathrm{~S} \cdot \mathrm{cm}^{-1}$ at $675 \mathrm{~K}$ to $3.10^{-3} \mathrm{~S} \cdot \mathrm{cm}^{-1}$ at $952 \mathrm{~K}$. This shows that, from the equivalent electrical circuit aspect, a variable resistor $(r)$, depending on the temperature, must be taken into account. It also means that the load impedance is going to change during the heating cycle progress. Thereafter, the electrical circuit can be simplified as shown on Figure 4(b). On it, the load

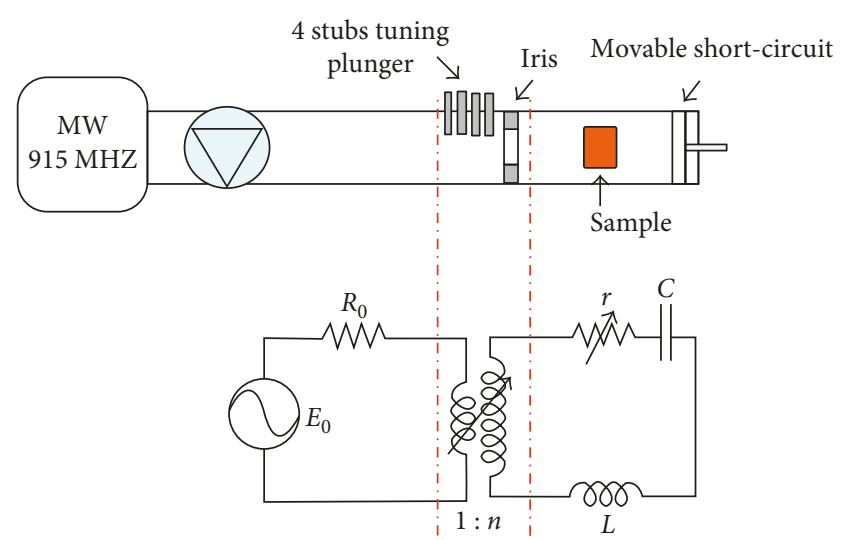

(a)

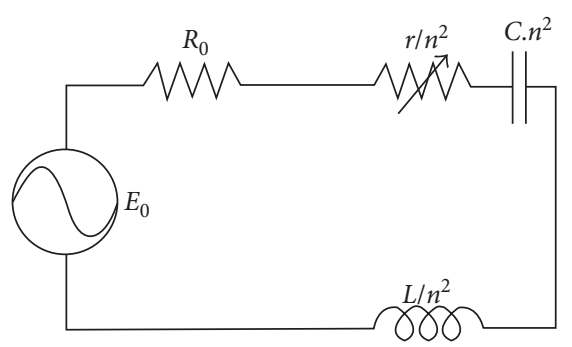

(b)

FIgURE 4: (a) Basic equivalent circuit of the microwave heating process. (b) Equivalent electrical circuit with load impedance referred to the primary side of the transformer.

impedance is referred to the primary side of the transformer, so that the transformer is removed from the electrical circuit. From this simple analogous electrical circuit, the optimal conditions to improve the power transfer from the source to the load, and to define a satisfactory strategy for designing the temperature regulation block function diagram, can be found.

2.4. Optimal Power Transfer Conditions and Block Function Diagram. From the equivalent electrical circuit (Figure $4(\mathrm{~b})$ ), the coupling coefficient $(\beta)$ can be defined as follows:

$$
\beta=\frac{R_{0} n^{2}}{r}
$$

The optimal power transfer will be achieved when the power losses into the load equals the power losses into the input impedance $\left(R_{0}\right)$. This condition means

$$
R_{0}=\frac{r}{n^{2}} \text {. }
$$

Therefore, the coupling coefficient equals $\beta=1$. It is useful to define the module of the reflection coefficient $(\rho)$ which can be expressed as follows:

$$
\rho=\frac{\beta-1}{\beta+1} \text {. }
$$

The reflection coefficient is the amplitude of the reflected voltage wave normalized to the amplitude of the incident voltage wave. When the load impedance ideally matches to 


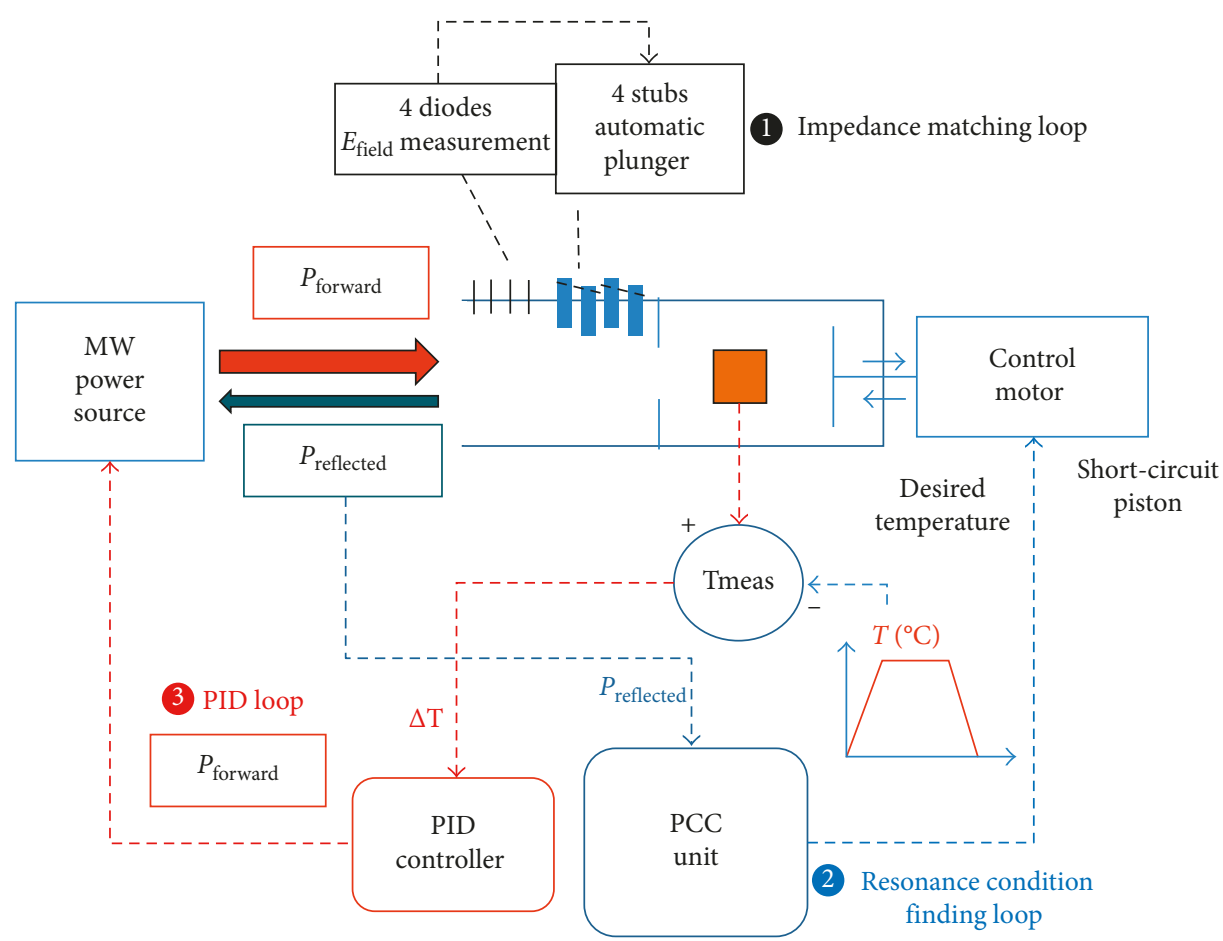

FIGURE 5: Block function diagram of the overall $915 \mathrm{MHz}$ microwave process designed to fully automatize the temperature regulation with resonance tuning and impedance matching.

the input impedance, the reflected voltage equals zero and the reflection coefficient becomes zero. The last useful expression is the ratio of the reflected microwave power $\left(P_{\text {reflected }}\right)$ to the forwarded microwave power $\left(P_{\text {forward }}\right)$, linked to each other by the following equation:

$$
\frac{P_{\text {reflected }}}{P_{\text {forward }}}=\rho^{2} .
$$

In order to fully automatize the $915 \mathrm{MHz}$ microwave heating process, the block function diagram (Figure 5) has been implemented. An independent loop, labeled (1), was first implemented to make sure that the load impedance matches with the line impedance. Considering the analogous electrical circuit, this means that the " $n$ " turn value changes automatically so that the $\beta$ value remains close to one. This loop needs to be running during the entire thermal cycle as the load impedance varies with temperature (the $r$ value is obviously changing, see (1)). Once the impedance matching is accommodated, the resonance conditions need to be tuned as well. To do so, a resonance finding loop has been implemented as well (see the loop labeled (2). The latter is working in adjusting the cavity length during the thermal cycle. The transverse electric (TE 105) mode is tuned so that the sample, located in the center of the cavity, is subjected to a maximum of the electrical field ( $E$ field). Another loop, labeled (3), was implemented to calculate and command the microwave forward power $\left(P_{\text {forward }}\right)$ needed to follow-up the desired temperature cycle, in using an adaptive PID module (proportional, integer, and derivative). The whole system is controlled by a personal computer (PCC unit).

\subsection{Applications of the As-Developed Microwave Process}

2.5.1. Microwave Sintering of $\mathrm{MgO}$-Stabilized $\mathrm{ZrO}_{2}$-Based Ceramic Tube. In order to test our process, a green zirconiabased sample made of an $\mathrm{MgO}$ ( 2-3 weight \%) stabilized zirconia material has been sintered using a programmed multistep heating cycle shown in Figure 6(a). The green samples (green density $\sim 2.9 \mathrm{~g} / \mathrm{cm}^{3}$ or $\sim 51 \%$ of the theoretical density value) were provided by the SOLCERA company and shaped by thermoplastic injection. After subjecting the sample to a thermal cycle in a conventional furnace for the removal of the organic binders and plasticizers, the cylinder (diameter $5.6 \mathrm{~mm}$, height $31.8 \mathrm{~mm}$, and thickness $0.9 \mathrm{~mm}$ ) has been sintered in air in our $915 \mathrm{MHz}$ cavity, using the thermal cycle shown in Figure 6(a). For confidential reasons, no additional details can be given regarding the preparation of the samples. However, the validation of the process being our goal, those details are unnecessary. The sintering thermal cycle has involved four heating ramps, respectively, at $30^{\circ} \mathrm{C} / \mathrm{min}$ (from $400^{\circ} \mathrm{C}$ to $1000^{\circ} \mathrm{C}$ ), $10^{\circ} \mathrm{C} / \mathrm{min}$ (from $1000^{\circ} \mathrm{C}$ to $1400^{\circ} \mathrm{C}$ ), $5^{\circ} \mathrm{C} / \mathrm{min}$ (from $1400^{\circ} \mathrm{C}$ to $1500^{\circ} \mathrm{C}$ ), and finally at $2.5^{\circ} \mathrm{C} / \mathrm{min}$ from $1500^{\circ} \mathrm{C}$ to $1515^{\circ} \mathrm{C}$. This multistep thermal cycle has been chosen in order to evaluate the dynamics of the system and to observe how the different ramps are managed. In order to evaluate the $P, I$, and $D$ parameters (loop (3), a fixed microwave forward power of $\sim 900 \mathrm{~W}$ is, first of all, applied. The temperature increase-as seen on the curve (see the dashed line) - is recorded and analyzed so that the initial PID parameters are calculated (thereafter, a selftuning adaptive PID has been used through the use of an adaptive PID controller from the Eurotherm 2408 model). Afterwards, the system works by itself and the actual 


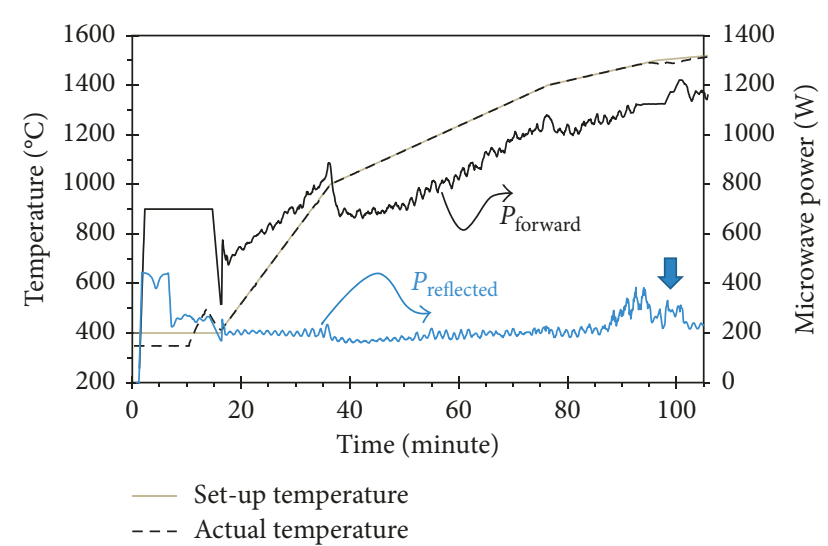

(a)

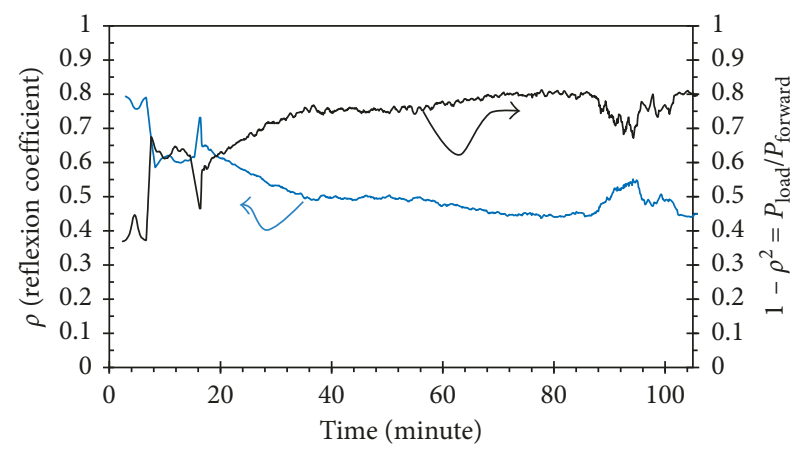

(b)

Figure 6: (a) Curves of the set-up and actual temperatures versus time and curves of the forwarded and reflected microwave power versus time during the microwave sintering of $\mathrm{MgO}$-stabilized zirconia. (b) Curves of the reflexion coefficient $(\rho)$ and $\left(1-\rho^{2}\right)$ versus time during the microwave sintering of zirconia-based material.

temperature automatically follows up the programmed temperature cycle. It can be seen that the actual temperature fits well with the programmed cycle and that the changes of the heating ramps are well managed. On the curve shown in Figure 6(a), it can be seen that the forward power continuously varies from $400 \mathrm{~W}$ at the beginning of the process to $1200 \mathrm{~W}$ when the highest temperature is reached. During the heating process, the reflected power does not vary much and its value remains close to $200 \mathrm{~W}$.

At the highest temperature, its value slightly increases up to $400 \mathrm{~W}$ before decreasing to $250 \mathrm{~W}$ at the end of the process (the arrow), whereas the actual temperature still follows up the desired cycle. It shows that the dynamic response is good enough to follow-up, even at a high temperature, a specific temperature cycle. From the forwarded and reflected powers, the reflexion coefficient $(\rho)$ has been calculated and plotted versus time (Figure 6(b)). Its initial value is $\sim 0.8$, but it rapidly decreases to $\sim 0.45$, showing that the tuning process (including both the impedance matching (loop(1)) and the resonance condition finding loop (loop(2)) are properly working. From the $\rho$ value, the ratio of the loaded power into the cavity over the forwarded power was plotted versus time (Figure 6(b)). This information gives the amount of the incident microwave power stored into the applicator, that is, the useful power. It is a good measure of the efficiency of the process. Once the program is running, it can be seen that this ratio rapidly increases to achieve a stable value around 80\% (Figure 6(b)). This ratio shows good impedance matching, satisfactory resonance conditions, and high process efficiency.

Figure 7 shows the green zirconia sample and the one being sintered by microwave heating. After sintering, the sample density, measured by the Archimedes method reaches $\sim 98 \%$ of the theoretical value. Moreover, it can be clearly seen that the sample mechanical integrity is very satisfactory (no cracks), and that the microwave sintering has led to produce a very homogeneous piece. As expected, a fine microstructure (Figure $7(\mathrm{~b})$ ) composed of both cubic and tetragonal phases is observed by Scanning Electron Microscopy (SEM Zeiss EVO MA 15).

\subsubsection{Microwave Sintering of Square-Shaped $\mathrm{MgAl}_{2} \mathrm{O}_{4}$} Ceramic. Green square shape $\left(65 \times 65 \times 12 \mathrm{~mm}^{3}\right) \mathrm{MgAl}_{2} \mathrm{O}_{4}$ (Baikowski S30CR, >99\% pure) samples were prepared by the SOLCERA company. The green density was approximately $\sim 52 \%$ of the theoretical one. To evaluate the reproducibility of the as-developed MW process, several pieces were microwave sintered using quite the same experimental conditions as those previously described. For this material, the programmed thermal cycle is given in Figure 8(a). It resembles the one used for zirconia, apart from the last heating ramp@ $2.5^{\circ} \mathrm{C} / \mathrm{min}$, which is being replaced by a dwell @ $1500^{\circ} \mathrm{C}$ for 5 minutes. Three samples were sintered using exactly the process previously described and using the thermal cycle (Figure 8(a)). In each case, homogeneous sintered pieces were obtained (Figure 8(b)) with similar densities around 96-97\% (measured by the Archimedes method). The samples microstructures were observed by the Scanning Electron Microscopy, and a typical microstructure is shown in Figure 8(c). This observation clearly shows a homogeneous and dense microstructure which confirms the satisfactory reproducibility of the as-developed $915 \mathrm{MHz}$ microwave process.

\section{Conclusion}

This study describes the development of an original $915 \mathrm{MHz}$ single-mode microwave cavity which is fully instrumented and automatized in order to regulate multistep temperature heating cycles up to $1600^{\circ} \mathrm{C}$ for material processing and sintering. At first, the whole system was described using a simple analogous electrical circuit which allows to clearly point out the different parameters that need to be controlled (tuning of the resonance conditions and impedance matching). From this electrical circuit, a block function diagram has been designed and implemented using automatic impedance-matching tuning plungers and a motorized short circuit termination. The as-developed process was successfully used to sinter different ceramic pieces, including zirconia tubes and square-shaped spinel materials by subjecting pieces to a programmed multistep thermal cycle. The process has 


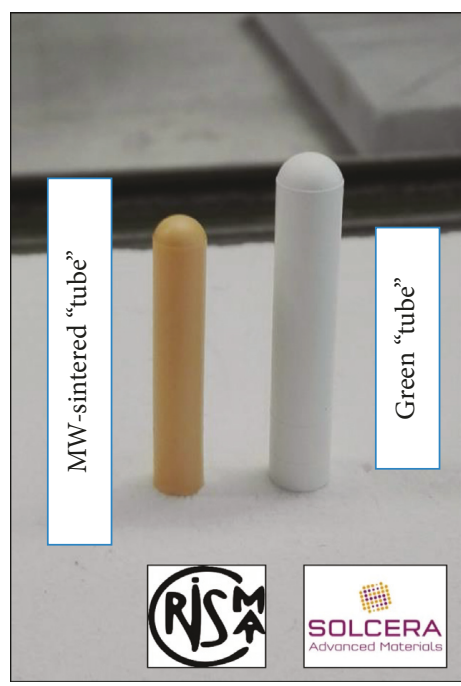

(a)

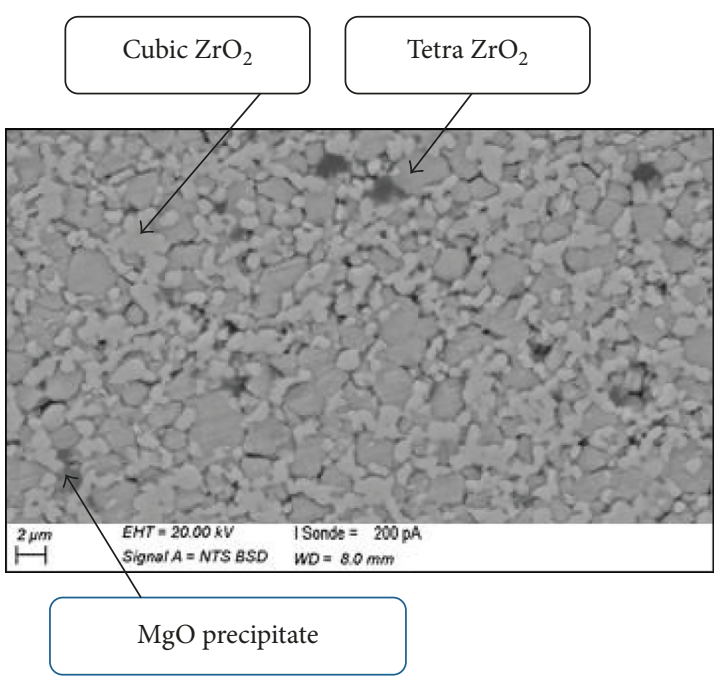

(b)

Figure 7: (a) Photograph showing the zirconia material tube before and after microwave sintering. (b) SEM microstructure of MgOstabilized microwave-sintered zirconia.

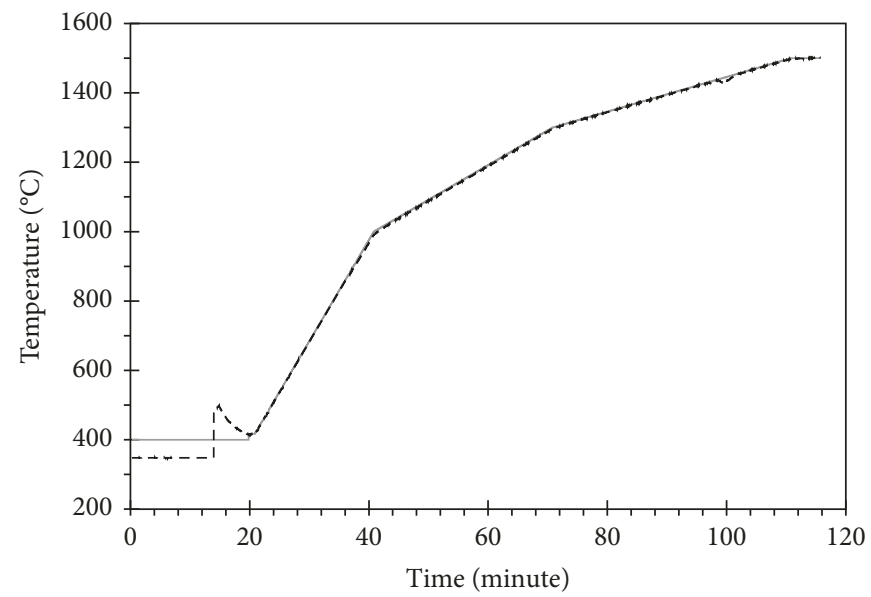

- Set point temperature $\left({ }^{\circ} \mathrm{C}\right)$

- - - Measured temperature $\left({ }^{\circ} \mathrm{C}\right)$

(a)

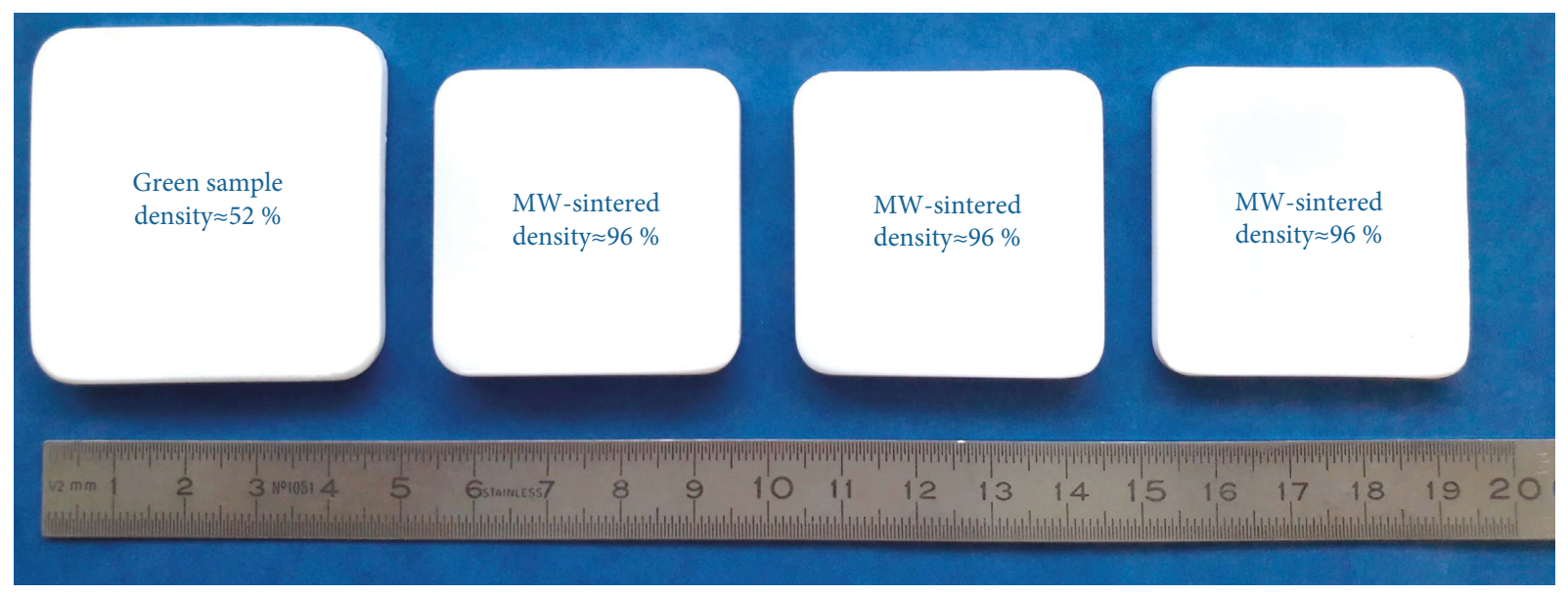

(b)

Figure 8: Continued. 


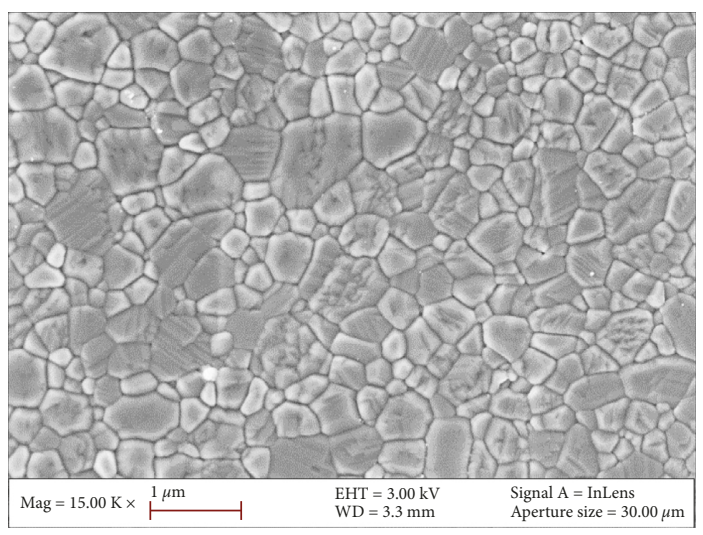

(c)

Figure 8: (a) Curves of the set-up and actual temperatures versus time for sintering $\mathrm{MgAl}_{2} \mathrm{O}_{4}$ square shape samples, (b) photograph showing the spinel-based material samples before and after microwave sintering, and (c) typical SEM microstructure recorded on $\mathrm{MgAl}_{2} \mathrm{O}_{4}$ microwave sintered .

proven its reliability, efficiency, and autonomy, opening up the path to industrial applications of microwave processing of materials at high temperature.

\section{Data Availability}

The data sets generated during and/or analyzed during the current study are available from the corresponding author on reasonable request.

\section{Conflicts of Interest}

The authors declare that there are no conflicts of interest regarding the publication of this paper.

\section{Acknowledgments}

The authors acknowledge Christelle Bilot and Anthony Bilot for their valuable assistance in conducting the experimental work. This work was supported by the Direction Générale de l'Armement (DGA) through the projects BAMBI (Ref. ANR-11-ASTR-0025) and MAMBO (Ref. ANR-16ASMA-0003). The authors would also like to thank the Solcera Advanced Material Company (Evreux) and the "Conseil Régional de Normandie" for supporting this work.

\section{References}

[1] H. J. Kitchen, S. R. Vallance, J. L. Kennedy et al., "Modern microwave methods in solid-state inorganic materials chemistry: from fundamentals to manufacturing," Chemical Reviews, vol. 114, no. 2, pp. 1170-1206, 2014.

[2] K. H. Brosnan, G. L. Messing, and D. K. Agrawal, "Microwave sintering of alumina at $2.45 \mathrm{GHz}$," Journal of the American Ceramic Society, vol. 86, no. 8, pp. 1307-1312, 2003.

[3] R. R. Menezes and R. H. G. A. Kiminami, "Microwave sintering of alumina-zirconia nanocomposites," Journal of Materials Processing Technology, vol. 203, no. 1-3, pp. 513517, 2008.

[4] R. R. Mishra and A. K. Sharma, "Microwave-material interaction phenomena: heating mechanisms, challenges and opportunities in material processing," Composites Part A: Applied Science and Manufacturing, vol. 81, pp. 78-97, 2016.

[5] M. Oghbaei and O. Mirzaee, "Microwave versus conventional sintering: a review of fundamentals, advantages and applications," Journal of Alloys and Compounds, vol. 494, no. 1-2, pp. 175-189, 2010.

[6] J. Croquesel, D. Bouvard, J.-M. Chaix, C. P. Carry, and S. Saunier, "Development of an instrumented and automated single mode cavity for ceramic microwave sintering: application to an alpha pure alumina powder," Materials \& Design, vol. 88, pp. 98-105, 2015.

[7] Y. V. Bykov, K. I. Rybakov, and V. E. Semenov, "Hightemperature microwave processing of materials," Journal of Physics D: Applied Physics, vol. 34, no. 13, pp. R55-R75, 2001.

[8] A. V. Starck and A. Mühlbauer, Handbook of Thermoprocessing Technologies, Vulkan-Verlag GmbH, Essen, Germany, 2005.

[9] J. Sun, W. Wang, and Q. Yue, "Review on microwave-matter interaction fundamentals and efficient microwave-associated heating strategies," Materials, vol. 9, no. 4, p. 231, 2016.

[10] R. Macaigne, S. Marinel, D. Goeuriot, C. Meunier, S. Saunier, and G. Riquet, "Microwave sintering of pure and $\mathrm{TiO}_{2}$ doped $\mathrm{MgAl}_{2} \mathrm{O}_{4}$ ceramic using calibrated, contactless in-situ dilatometry," Ceramics International, vol. 42, no. 15, pp. 16997-17003, 2016.

[11] G. J. Vogt, A. Regan, A. Rohlev, and M. Curtin, "Microwave process control through a traveling wave tube source," MRS Proceedings, vol. 430, 1996.

[12] G. Atanasova and N. Atanasov, "Tuning, coupling and matching of a resonant cavity in microwave exposure system for biological objects," Electromagnetic Biology and Medicine, vol. 32, no. 2, pp. 218-225, 2013.

[13] J. F. Gerling, Waveguide Components and Configurations for Optimal Performance in Microwave Heating Systems, Technical Document, Gerling Applied Engineering, Inc., Modesto, CA, USA, 2000.

[14] A. Das and S. K. Das, Microwave Engineering 2E, Tata McGraw-Hill Education, New York, NY, USA, 2009.

[15] S. Heiroth, T. Lippert, A. Wokaun et al., "Yttria-stabilized zirconia thin films by pulsed laser deposition: microstructural and compositional control," Journal of the European Ceramic Society, vol. 30, no. 2, pp. 489-495, 2010. 


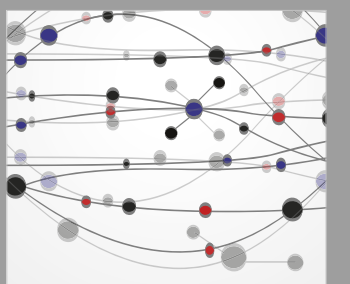

The Scientific World Journal
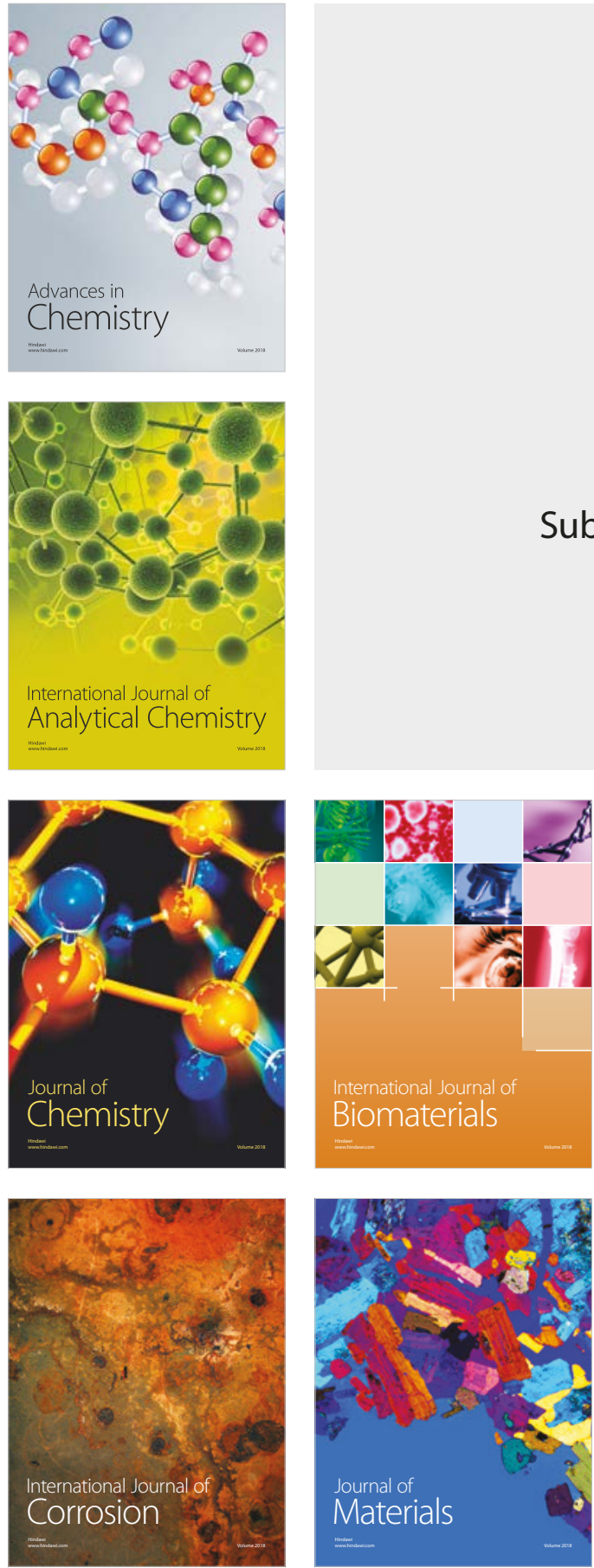

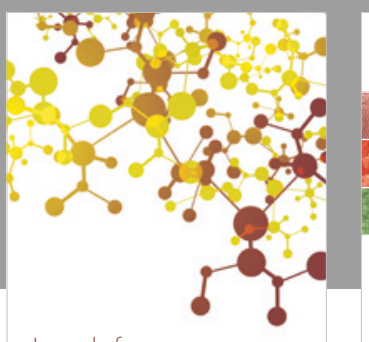

Journal of

Applied Chemistry
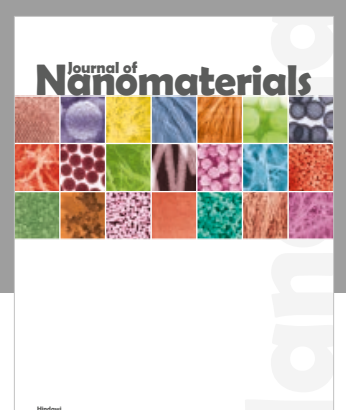

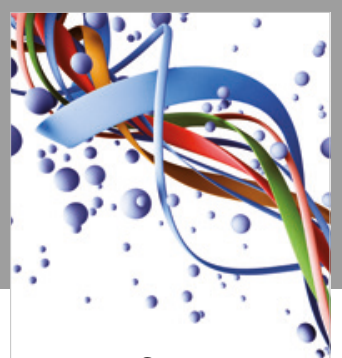

Scientifica

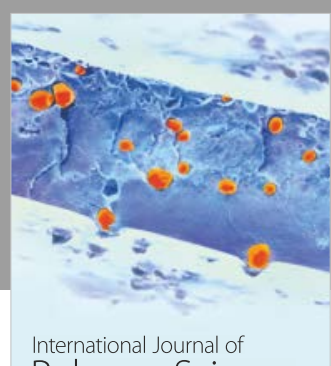

Polymer Science

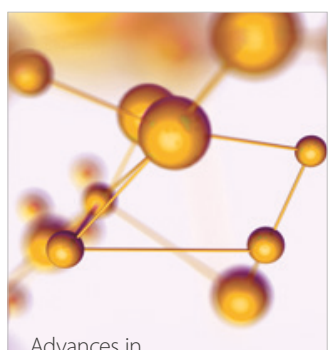

Physical Chemistry
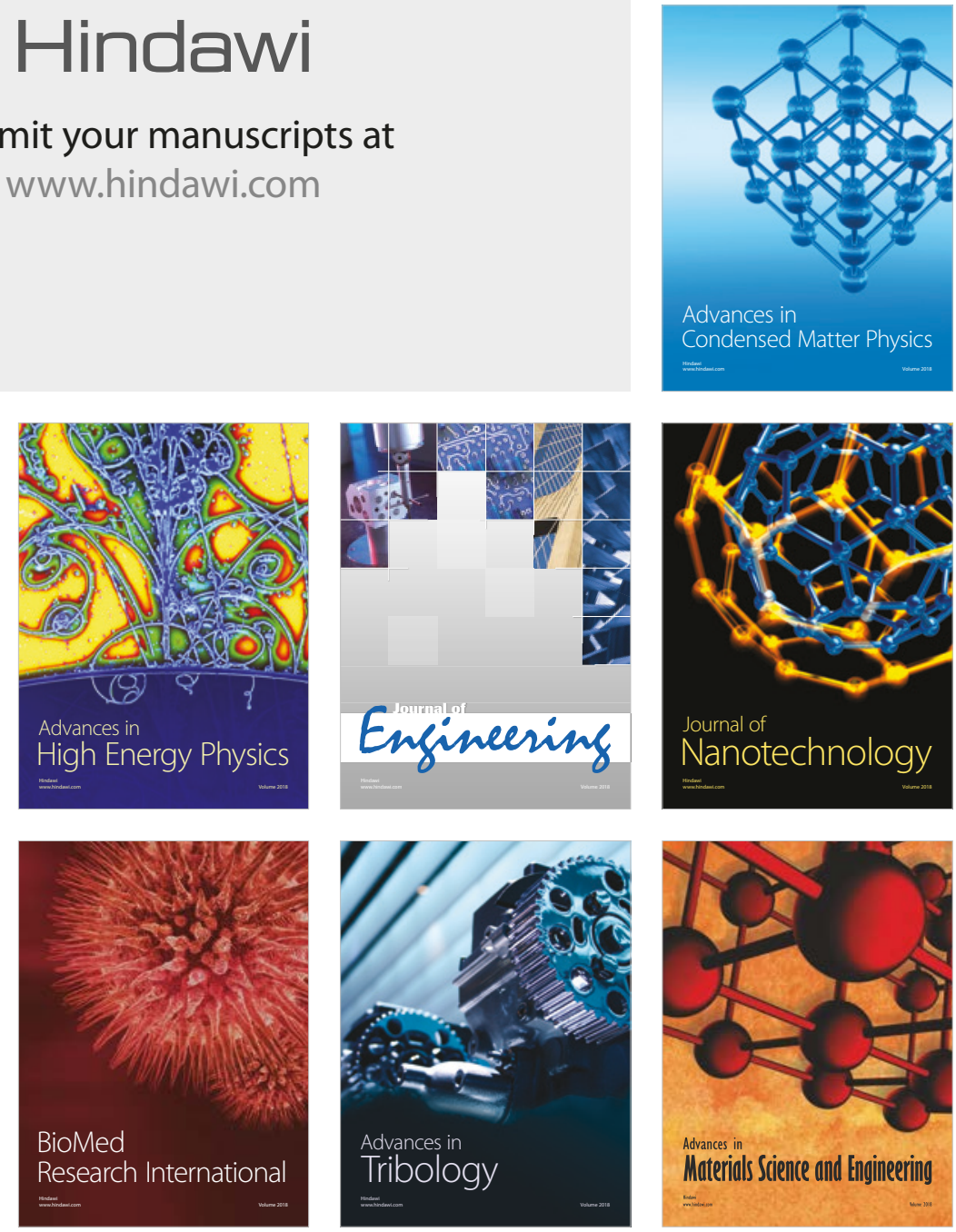